\title{
ESTÁGIO CURRICULAR SUPERVISIONADO EM GEOGRAFIA: EXPERIÊNCIA DO ENSINO REMOTO DURANTE O PERÍODO DE ISOLAMENTO SOCIAL (COVID-19)
}

\section{SUPERVISED CURRICULAR INTERNSHIP IN GEOGRAPHY: REMOTE TEACHING EXPERIENCE DURING THE SOCIAL ISOLATION PERIOD (COVID-19)}

\section{PRÁCTICAS CURRICULARES SUPERVISADAS EN GEOGRAFÍA: EXPERIENCIA DE ENSEÑANZA A DISTANCIA DURANTE EL PERIODO DE AISLAMIENTO SOCIAL (COVID-19)}

\author{
Caio Carvalho Santos ${ }^{1}$ https://orcid.org/0000-0003-2636-9247 \\ João Vitor Ferreira Fernandes ${ }^{2}$ https://orcid.org/0000-0002-5368-0017 \\ Amanda Karolayne Rodrigues Silva ${ }^{3}$ https://orcid.org/0000-0001-5786-1176 \\ Maria Heloisa Pinheiro Dias ${ }^{4}$ https://orcid.org/0000-0003-4597-8531 \\ Rahyan de Carvalho Alves ${ }^{5}$ https://orcid.org/0000-0001-7225-5959
}

\footnotetext{
${ }^{1}$ Graduando em Geografia - Universidade Estadual de Montes Claros. E-mail: carvalhocaiosantos.2018@ gmail.com

${ }^{2}$ Graduando em Geografia - Universidade Estadual de Montes Claros. E-mail: vitoruni1998@gmail.com

${ }^{3}$ Graduanda em Geografia - Universidade Estadual de Montes Claros. E-mail:

${ }^{4}$ Graduanda em Geografia - Universidade Estadual de Montes Claros. E-mail: mariahelopi3@ gmail.com

${ }^{5}$ Doutorando em Geografia pela UFMG e Professor da Universidade Estadual de Montes Claros. E-mail: rahyan.alves@unimontes.br
}

\section{RESUMO}

No início do ano de 2020, o mundo foi surpreendido pela COVID-19 e as medidas sanitárias adotadas para conter a disseminação do Novo Corona vírus fizeram com que a sociedade se submetesse a um processo de reeducação dos seus hábitos. As transformações tangenciaram desde o ambiente de trabalho, como também o sistema educacional, e em todas as áreas houve a necessidade de se adequar. Sendo assim, o objetivo deste trabalho consiste em relatar as experiências vivenciadas pelos acadêmicos do sétimo período (noturno) do curso de Licenciatura em Geografia da Universidade Estadual de Montes Claros (sede) nas atividades referentes ao período de regência na disciplina de Estágio Curricular Supervisionado. Os procedimentos metodológicos foram: consulta bibliográfica e análise de decretos federais, da resolução estadual para aplicação de ensino remoto emergencial e da Lei de Diretrizes e Bases da Educação Nacional e apresentação de atividades desenvolvidas durante o período de regência. Dentre os resultados foi possível observar as práticas e estratégias de ensino adotadas por cada escola-parceira e, ao passo que, também foi possível analisar as disparidades que eram concebidas desde as relações entre, docente, discente e os pais, como quanto as ferramentas utilizadas.

Palavras-chaves: Estágio Supervisionado. Ensino Remoto. Isolamento Social. Ensino de Geografia. 
Estágio Curricular Supervisionado em Geografia: experiência do ensino remoto durante o período de isolamento social (Covid-19)

Caio Carvalho Santos; João Vitor Ferreira Fernandes; Amanda Karolayne Rodrigues Silva; Maria Heloisa Pinheiro Dias; Rahyan de Carvalho Alves

\begin{abstract}
In the beginning of 2020, the world was surprised by COVID-19 and the sanitary measures adopted to contain the spread of the New Corona virus made society undergo a process of re-education of its habits. The transformations touched the work environment, as well as the educational system, and in all areas, there was the need to adapt. Thus, the aim of this paper is to report the experiences of the seventh period students (night shift) of the Geography undergraduate course at the State University of Montes Claros (headquarters) in the activities related to the period of regency in the discipline of Supervised Curricular Internship. The methodological procedures were: bibliographic consultation and analysis of federal decrees, the state resolution for the application of emergency remote teaching and the Law of Directives and Bases of National Education and presentation of activities developed during the regency period. Among the results it was possible to observe the teaching practices and strategies adopted by each school-partner and, at the same time, it was also possible to analyze the disparities, which were conceived since the relations between, teacher, student and parents, as for the tools used.
\end{abstract}

Keywords: Supervised internship. Remote teaching. Social isolation. Geography Education.

\title{
RESUMEN
}

A principios de 2020, el mundo fue sorprendido por el COVID-19 y las medidas sanitarias adoptadas para contener la propagación del nuevo virus Corona hicieron que la sociedad se sometiera a un proceso de reeducación de sus hábitos. Las transformaciones se extendieron tanto al ámbito laboral como al sistema educativo, y en todos los ámbitos hubo que adaptarse. Así, el objetivo de este trabajo es relatar las experiencias de los alumnos del séptimo período (nocturno) del curso de pregrado en Geografía de Universidad Estatal de Montes Claros (sede) en actividades relacionadas con el período de regencia en la disciplina de Práctica Curricular Supervisada. Los procedimientos metodológicos: la consulta bibliográfica y el análisis de los decretos federales, la resolución estatal para la aplicación de la tele enseñanza de emergencia y la Ley de Directrices y Bases de la Educación Nacional y la presentación de las actividades desarrolladas durante la regencia. Entre los resultados fue posible observar las prácticas y estrategias de enseñanza adoptadas por cada escuela-socio y, al mismo tiempo, fue posible analizar las disparidades que fueron concebidas las relaciones entre, profesor, alumno y padres, en cuanto las herramientas utilizadas.

Palabras clave: Prácticas supervisadas. Enseñanza a distancia. Aislamiento social. Enseñanza de la Geografía

\section{INTRODUÇÃO}

No início do ano de 2020, o mundo inteiro, de forma atípica, foi surpreendido pela COVID-19 - uma doença respiratória que inicialmente surgiu em dezembro de 2019 na China. Devido ao seu alto risco de contágio e a rápida proliferação do vírus, a nível mundial, a Organização Mundial da Saúde declara em 11 de março de 2020 estado de pandemia, e a partir daí são recomendadas medidas restritivas, tal como o isolamento social buscando 
Estágio Curricular Supervisionado em Geografia: experiência do ensino remoto durante o período de isolamento social (Covid-19)

Caio Carvalho Santos; João Vitor Ferreira Fernandes; Amanda Karolayne Rodrigues Silva; Maria Heloisa Pinheiro Dias; Rahyan de Carvalho Alves

minimizar a circulação e aglomeração de pessoas, a fim de evitar mais contaminações e, numa situação-limite, evitar óbitos (CAMACHO et al., 2020; OMS, 2020).

Pesquisas e estudos para o tratamento da doença começaram a se desenvolver, contudo durante todo esse processo as medidas de isolamento social foram implementadas com a finalidade de minimizar o contato físico entre as pessoas e como consequência diminuir a propagação do vírus ${ }^{6}$. Dentre as principais medidas restritivas de isolamento realizadas pelo poder público podem ser destacadas as seguintes: $i$ ) a proibição de apresentações artísticas com a presença de pessoas, $\mathrm{ii}$ ) o fechamento de comércio de serviços não essenciais e das instituições de ensino e, iii) a promoção de lockdown (OMS, 2020; SOUZA; MIRANDA, 2020).

O confinamento destacado gerou vários desconfortos na sociedade, e os governos do mundo inteiro foram obrigados a tomar decisões imediatistas de ordem econômico-social. Em relação à educação, no dia 26 de abril de 2020 cerca de $90 \%$ dos alunos de todos os países ficaram impedidos de frequentar aulas presenciais. Países como França, Espanha, Portugal e Inglaterra adotaram medidas de vinculação das atividades escolares com o uso das tecnologias digitais, contudo apresentaram dificuldades no processo de aprendizagem, pois parte da população não possuía acesso às tecnologias da informação e comunicação disponíveis, impossibilitando os professores de acompanharem seus alunos (ARRUDA, 2020).

Alves (2020) afirma que as atividades pedagógicas executadas por meio digitais, e outras não presenciais, também resultaram em um aumento significativo da demanda de trabalhos executados pelos profissionais envolvidos na área da educação. Além da organização e adaptação de tarefas feitas em casa, devido à realidade do isolamento social, houve tempo extra gasto para que os professores pudessem compreender o uso de alguns recursos e meios eletrônicos disponíveis para a elaboração das suas atividades e comunicação com os alunos, tais como a partir dos aplicativos gratuitos mais utilizado no Brasil, a saber: i) Google Meet, ii) Google Classroom, iii) Skype, iv) Zoom, v) WhatsApp, vi) redes sociais (exemplo: facebook) dentre outros.

Miléo et al (2020) complementam que a jornada de trabalho acrescida aos professores resulta em um processo de profissionalização uma vez que, além da elaboração de aulas, o tempo que os docentes teriam para descansarem ou se qualificarem foi substituído por uma gama de novas atividades como orientação de pais no acompanhamento dos trabalhos

\footnotetext{
${ }^{6}$ Até o dia 12 de abril de 2021 atingiu, no Brasil, os seguintes números: 13.517 .808 casos de contaminação e 354.617 óbitos - no Mundo, chegamos a infeliz marca de 2.949.096 mortes acometidos pelo COVID-19 (BRASIL, 2021).
} 
Estágio Curricular Supervisionado em Geografia: experiência do ensino remoto durante o período de isolamento social (Covid-19)

Caio Carvalho Santos; João Vitor Ferreira Fernandes; Amanda Karolayne Rodrigues Silva; Maria Heloisa Pinheiro Dias; Rahyan de Carvalho Alves

educacionais de seus filhos e longas reuniões de cunho didático-pedagógicas - que, por vezes, possui enfoque nas questões de natureza administrativa e burocrática. De uma forma geral, o aumento de atividades dedicadas à área educacional, somadas ao isolamento social e pouco tempo de descanso, além de comprometerem o ensino ofertado aos alunos, contribui para o prejuízo da vida dos profissionais na área docente - especialmente devido à dificuldade dos professores realizarem a divisão do tempo para o trabalho e o tempo para a vida social, provocando o aumento de casos de síndrome de Burnout (síndrome do esgotamento profissional).

No Brasil, o fechamento das instituições de ensino deram-se por meio dos decretos $n^{\circ}$ 343 e 345 publicados nos dias 17 e 19 de março e os no 473 e 544 publicados nos dias 19 de maio e 16 de junho (BRASIL, 2020a; BRASIL, 2020b; BRASIL, 2020c; BRASIL, 2020d), sendo que todos esses decretos estabeleceram normas excepcionais enquanto o período pandêmico do Novo Corona vírus (COVID-19) perdurar-se, permitindo, desta forma, a substituição das aulas presenciais por aulas não presenciais até 31 de dezembro de 2020.

Em Minas Gerais, o Conselho Estadual de Educação prescreve determinações através da resolução CEE $n^{\circ} 474$ de 08 de maio para que atividades não presenciais fossem autorizadas para a educação básica e ensino superior como forma de cumprimento da carga horária mínima anual (CEEMG, 2020). Para atender a rede pública de ensino, do ensino fundamental ao médio, planos de estudos tutorados (PET) foram confeccionados em três modalidades, sendo elas: regular, integral e especial, vídeo aulas também foram transmitidas pela "Rede Minas" e disponibilizadas no aplicativo "Conexão Escola", no site "Estude em casa" e, também, no canal do Estado de Educação via "YouTube” (ESTUDE EM CASA, 2020; ESTÚDIO EDUCAÇÃO MG, 2020).

Diante dessa realidade de isolamento social e ensino remoto emergencial, o objetivo deste trabalho consiste em relatar algumas experiências vivenciadas pelos acadêmicos do sétimo período do curso de licenciatura (noturno) em Geografia da Universidade Estadual de Montes Claros (UNIMONTES - sede) nas atividades referentes ao período de regência proporcionado pela disciplina Estágio Curricular Supervisionado em Geografia, ocorrendo a imersão dos acadêmicos, no caso deste trabalho, respectivamente na Escola Estadual Tiburtino Pena, localizada no município de Francisco Sá-MG e, no município de Montes Claros-MG, na Escola Estadual Augusta Valle e em uma escola da rede particular.

Os procedimentos metodológicos foram organizados em duas etapas. A primeira constituiu-se de consulta bibliográfica a respeito das temáticas relacionadas a Pandemia causada pelo vírus COVID-19 e o papel do Estágio Supervisionado; análise de decretos 
Estágio Curricular Supervisionado em Geografia: experiência do ensino remoto durante o período de isolamento social (Covid-19)

Caio Carvalho Santos; João Vitor Ferreira Fernandes; Amanda Karolayne Rodrigues Silva; Maria Heloisa Pinheiro Dias; Rahyan de Carvalho Alves

federais, resolução estadual para aplicação de ensino remoto emergencial e Lei de Diretrizes e Bases da Educação Nacional (LDB). A segunda parte refere-se às atividades desenvolvidas durante o período de regência nas escolas.

A estrutura do trabalho é composta de três partes, primeiramente focou-se em articular a importância dos Estágios Curriculares Supervisionados nos cursos das licenciaturas; em seguida foi relatado as atividades realizadas no estágio e, por fim, foi relatado a experiência e os a desafios do ensino emergencial remoto durante o período de isolamento social, no contexto de cada turma das escolas anteriormente mencionadas.

\section{RESULTADOS E DISCUSSÃO}

De acordo com a Lei de Diretrizes e Bases da Educação Nacional - LDB - nº 9394/96 (BRASIL, 1996), em todos os cursos de licenciaturas é obrigatório a promoção do Estágio Curricular Supervisionado, cabendo às instituições de ensino superior pré-estabelecerem a carga horária e estarem de acordo com as determinações desta lei federal, para que desta maneira os acadêmicos possam cumprir com as determinações estabelecidas e concluírem plenamente a sua formação como profissional docente.

A formação dos profissionais da área docente é constituída em várias etapas na universidade, sendo que os momentos dedicados a execução dos estágios supervisionados, configuram a etapa em que os acadêmicos possam interagir com o contexto da vida escolar, bem como adquirir experiência sob orientação de um professor-regente, conjuntamente com o professor universitário, o qual assume o papel de professor-orientador.

Segundo Scalabrin e Molinari (2013), o Estágio Curricular Supervisionado é um processo necessário que visa aprimorar o aprendizado referente à profissão docente que será exercida no futuro e tem o papel de proporcionar ao acadêmico a articulação entre teoria e prática. Quando o acadêmico tem contato com as atividades desempenhadas durante o estágio, é fornecida a ele a compreensão da realidade em sala de aula, uma vez que dificuldades e possibilidades do cotidiano educacional brasileiro podem ser experienciados.

Os autores Freitas, Costa e Lima (2017), por sua vez, entendem o Estágio como um conjunto de saberes adquiridos durante a formação acadêmica e que por meio da investigação da realidade escolar pode desenvolver ações e diagnósticos do universo da educação de maneira problematizadora e, assim, entenderá melhor o seu mundo de trabalho. Desta forma a articulação das atividades exercidas pelos docentes da universidade, professores da escolacampo, em conjunto com os estagiários, favorecem a formação dos licenciados, uma vez que 
Estágio Curricular Supervisionado em Geografia: experiência do ensino remoto durante o período de isolamento social (Covid-19)

Caio Carvalho Santos; João Vitor Ferreira Fernandes; Amanda Karolayne Rodrigues Silva; Maria Heloisa Pinheiro Dias; Rahyan de Carvalho Alves

a identidade profissional docente é construída mediante as experiências adquiridas no contexto da parceria entre universidade e escola.

Quanto à finalidade do Estágio Curricular Supervisionado, pode ser entendida, nas palavras de Martins e Tonini (2016), como sendo:

[...] proporcionar a articulação entre conhecimentos teóricos e práticos e o desenvolvimento de estratégias e habilidades para lidar com as situações em sala de aula. Deve caracterizar-se como espaço de reflexão sobre aspectos teórico-práticos do processo ensino-aprendizagem, possibilitando ações propositivas capazes de dar conta dos desafios colocados pela docência (2016, p. 103-104).

Nesta perspectiva, podemos considerar o Estágio Curricular Supervisionado como a parte do curso em que o acadêmico pode adquirir a experiência mínima necessária para a atuação como profissional docente. O contato que os acadêmicos das licenciaturas possuem com as escolas de ensino básico possibilitam uma articulação com Universidade, o que favorece a integração da educação, uma vez que as instituições de ensino superior formam os licenciados e os mesmos, ao atuarem no ensino básico, podem colocar em prática todo o seu aprendizado adquirido no período da graduação.

Com a pandemia do COVID-19, ocorreu a suspensão das aulas presenciais, contudo a execução das atividades inerentes ao Estágio Curricular Supervisionado pôde ser realizada de maneira remota. As escolas supracitadas iniciaram suas atividades não presenciais a partir do mês de março de 2020, e o período de regência dos acadêmicos do sétimo período do curso de licenciatura em Geografia da Unimontes deu-se a partir do segundo semestre do mesmo ano, momento em que as diretrizes traçadas pelo governo estadual já estavam esclarecidas e a Universidade preparada para atuar com seus trabalhos de maneira remota.

A Escola Estadual Tiburtino Pena, localizada na zona urbana do município de Francisco Sá-MG, atende alunos tanto da área urbana quanto da área rural, respectivamente do $6^{\circ}$ ano Fundamental ao $3^{\circ}$ ano do ensino Médio. O desenvolvimento das disciplinas nessa escola ocorreu através de videoaulas disponibilizadas no aplicativo Conexão Escola e pelo Plano de Estudo Tutorado (PET). Além disso, a escola contou com o uso de recursos digitais como o WhatsApp e a utilização da plataforma Google Meet para as aulas online. Como avaliações foram realizadas: entrega do PET, prova diagnóstica da Secretaria de Estado de Educação de Minas Gerais (SEE-MG) e a Maratona Estudantil da Escola.

Em relação ao PET, esse material é uma ferramenta de estudo não presencial elaborado pela SEE-MG. Nesta proposta foram organizadas apostilas observando os conteúdos de cada disciplina, juntamente com exercícios adequados para cada ano de 
Estágio Curricular Supervisionado em Geografia: experiência do ensino remoto durante o período de isolamento social (Covid-19)

Caio Carvalho Santos; João Vitor Ferreira Fernandes; Amanda Karolayne Rodrigues Silva; Maria Heloisa Pinheiro Dias; Rahyan de Carvalho Alves

escolaridade, $1^{\circ}$ ao $9^{\circ}$ ano do ensino fundamental e $1^{\circ}$ ao $3^{\circ}$ do ensino médio. Para os estudantes que não têm acesso à internet, o PET é impresso pela escola e entregue ao aluno.

Ainda que a escola apresente empenho para oferecer suporte adequado aos alunos, mesmo em período remoto, os estudantes sem acesso aos meios tecnológicos foram notoriamente prejudicados, uma vez que não tiveram acesso às vídeo aulas, sendo também impossibilitados de tirar dúvidas com o professor quanto ao conteúdo estudado.

Quanto às atividades realizadas durante o estágio remoto, especialmente com a turma do $1^{\circ}$ ano do ensino médio, podem ser destacadas: adaptações das atividades propostas nos PETs, preparação e sistematização de vídeo, plantão para esclarecer dúvidas e gabarito/resolução de atividades dos PETs. Cabe mencionar que todas as atividades foram realizadas através dos recursos digitais, cujos objetivos eram auxiliar os alunos na compreensão dos conteúdos.

Os alunos da turma possuíam baixo poder aquisitivo, mas todos tinham acesso à internet, embora a maior parte deles acessasse as atividades através do celular, dado que poucos alunos da turma possuíam computador, e mesmo assim era difícil para que eles acompanhassem plenamente todas as atividades, pois não sabiam lidar com os recursos tecnológicos que detinham e nem possuíam apoio familiar para auxiliarem nessa tarefa. De um lado, muitos discentes não realizavam as atividades por falta de interesse e incentivo. Por outro lado, outros tinham dificuldades de acesso às mídias devido ao aparelho às vezes não suportar o recurso disponibilizado. Vale destacar que, às vezes, o envio dos exercícios dos PETs era postados com atraso nas plataformas digitais do Estado o que dificultava ainda mais a realização das atividades do professor e dos alunos em tempo hábil. Embora seja totalmente compreensível a falta de participação dos alunos em decorrência das dificuldades de acesso às mídias disponíveis para a realização das atividades, foi possível perceber que existe alunos no grupo de estudos do WhatsApp da escola, participando com questionamentos e debates/discussões sobre os conteúdos abordados do PET, e tal processo foi observado em todo o período do estágio.

O professor supervisor do estágio teve que se adaptar à nova rotina de aulas remotas sem nenhuma formação oferecida pelo Estado, desta forma apresentou dificuldades em elaborar as atividades pedagógicas por meios digitais e improvisação no desenvolvimento de metodologias que, por sua vez, não foram suficientemente atrativas para os alunos, resultando em desinteresse, falta de estímulo e produtividade de ensino inferior a presencial.

A Escola Estadual Augusta Valle, localizada no bairro Santa Laura, oferta o acesso ao ensino para os alunos do $6^{\circ}$ ano Fundamental ao $3^{\circ}$ ano do ensino Médio da zona urbana de 
Estágio Curricular Supervisionado em Geografia: experiência do ensino remoto durante o período de isolamento social (Covid-19)

Caio Carvalho Santos; João Vitor Ferreira Fernandes; Amanda Karolayne Rodrigues Silva; Maria Heloisa Pinheiro Dias; Rahyan de Carvalho Alves

Montes Claros-MG. E nesta escola as atividades de regência ocorreram com a turma do $1^{\circ}$ do ensino Médio, onde durante todo o ano letivo foram registradas as atividades escolares através do Plano de Ensino Tutorado - PET, a professora não ministrou aulas on-line, promovendo contato por mensagens via WhatsApp. Na escola, cada docente "apadrinhou" uma turma para ser o professor-referência, mantendo contato com os discentes e seus familiares e ou responsáveis. Pelo WhatsApp, o professor-referência motivava os alunos a realizarem as atividades dispostas nos PETs, tal como solicitando que os discentes sinalizassem presença, e sendo uma ponte para encaminhar as demandas da turma para a coordenação escolar e professores de outras disciplinas.

As atividades realizadas nessa escola se deram a partir, basicamente, da correção dos PETs e elaboração de videoaula sobre as matérias dos PETs na área da Geografia. Vale ressaltar que todas as atividades foram realizadas por meio dos recursos digitais, com o objetivo de ajudar os alunos a compreender o conteúdo. Os alunos desta escola possuem baixa renda aquisitiva, a maior parte possuía acesso à internet através do celular, poucos possuíam computador e os que não possuíam nenhum aparelho eletrônico recebiam as atividades impressas disponibilizadas na escola, cabendo ao aluno ir até a instituição para buscá-las.

O professor supervisor da turma não passou por nenhuma formação oferecida pelo Estado, apenas o PET lhe foi entregue como recurso didático para o ensino remoto emergencial, desta forma estratégias didático-pedagógicas foram improvisadas, contudo para atender os alunos a comunicação foi o principal problema enfrentado, uma vez que o WhatsApp era a única forma de envio de mensagens entre o professor e os alunos e, por vez, os que não possuíam o acesso a essa rede social, apenas com a inda presencial na escola conseguiam informações das atividades a serem desenvolvidas.

A pandemia nos colocou frente ao desafio de pensar a escola, nos retirando da sala de aula física, ambiente que normalmente foi o lugar de estabelecer os vínculos principais de mediações de conhecimento. A função docente desempenhada dentro desse lugar, onde professores, alunos e toda comunidade escolar se habituaram, já não é o espaço delimitado para essa função. Sempre falamos na transformação da escola, que precisamos repensar novos modelos, eis que a pandemia nos obrigou a mudar e a buscar a construir o sentido de lugarescolar no meio digital.

A adoção do ensino remoto trouxe à tona as dificuldades dos atores do sistema de educação pública com a prática. Secretarias de educação tiveram de se adaptar para oferecer aulas pela internet, por aplicativos, por mensagens e por outras redes sociais. Escolas e professores tentam manter contato com os alunos. Os professores precisaram se reinventar, 
Estágio Curricular Supervisionado em Geografia: experiência do ensino remoto durante o período de isolamento social (Covid-19)

Caio Carvalho Santos; João Vitor Ferreira Fernandes; Amanda Karolayne Rodrigues Silva; Maria Heloisa Pinheiro Dias; Rahyan de Carvalho Alves

redesenhando o processo de ensino, enfrentando muitas dificuldades como: $i$ ) preparar as atividades para os alunos e atendê-los a qualquer momento, ii) cumprir as burocracias exigidas pela Secretaria de Educação e, ainda, iii) lecionar on-line com a presença de poucos alunos.

$\mathrm{Na}$ escola da rede particular de ensino em Montes Claros-MG, o estágio remoto foi executado em duas turmas, uma do primeiro e outra do segundo ano do ensino médio. As aulas foram executadas com a utilização do Google Meet, como ferramenta principal, devido a sua capacidade de transmissão em vídeo em tempo real e, outras ferramentas tais como o Google Classroom, foram utilizadas para facilitar a conexão com o discente e desenvolver as práticas de ensino alternativas, que possibilitasse alcançar o aluno mesmo com as dificuldades encontradas com a necessidade de se readaptar com os novos modelos de aula.

Através de pesquisa qualitativa, observou-se no estágio realizado que os alunos da escola particular em geral são residentes da área urbana, adolescentes entre 14 e 16 anos. Do ponto de vista socioeconômico, estão inseridos no contexto de renda familiar das classes média e classe média baixa, o que facilita quanto ao acesso as ferramentas básicas para a execução do ensino remoto (internet, dispositivos eletrônicos etc.). Vale destacar que a escola disponibiliza programas de bolsas de estudo parciais e totais, contemplando em torno de $25 \%$ do total de alunos o educandário.

Ao longo do estágio foi possível observar que a escola agia conjuntamente com os pais dos alunos, contava com suporte e apoio dos docentes, o que facilitava o desenvolvimento das aulas. Os alunos possuíam acesso às ferramentas de ensino necessárias para executarem as aulas remotas, sendo que eles dispunham de internet em casa e, em geral, possuíam mais de um aparelho eletrônico (celulares, tablets, computadores etc.) que atendiam as atividades desenvolvidas.

Nas turmas do primeiro e segundo ano do ensino médio, as principais experiências adquiridas durante o estágio foram o desenvolvimento de banco de questões objetivas focadas em opções de múltipla escolha, seguindo os padrões de vestibulares locais e nacionais, e outras questões de caráter discursivo (abertas) também foram elaboradas e discutidas com os alunos, com a finalidade de extrair dos discentes uma maior reflexão sobre as temáticas estudadas e incitá-los a exercitar a escrita e diálogos propositivos.

$\mathrm{Na}$ turma do primeiro ano, aulas expositivas foram elaboradas com a utilização de slides e outras aulas interativas com o uso de jogos eletrônicos foram construídas com a finalidade de mediar o processo de ensino e aprendizagem da temática "Matrizes energéticas". Neste caso o uso do Jogo Sim City 5, possuía mecanismos necessários ao desenvolvimento de 
Estágio Curricular Supervisionado em Geografia: experiência do ensino remoto durante o período de isolamento social (Covid-19)

Caio Carvalho Santos; João Vitor Ferreira Fernandes; Amanda Karolayne Rodrigues Silva; Maria Heloisa Pinheiro Dias; Rahyan de Carvalho Alves

atividades com base no conteúdo apresentado, pois se tratava de um simulador de construção de cidades (Vide Figura 1).

Figura 1: Aula sobre matrizes energéticas (uso do Sim City).

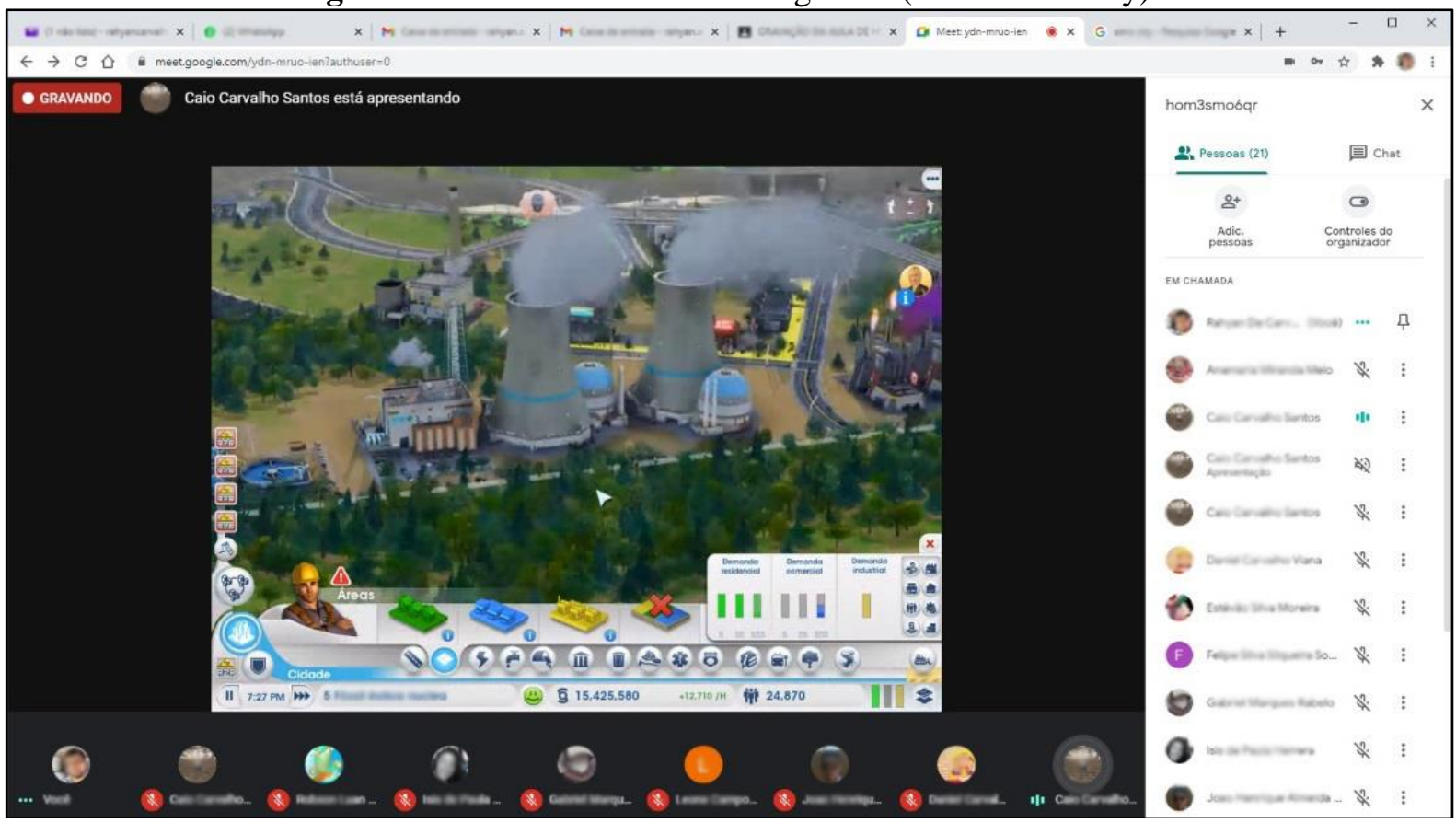

Fonte: Próprios autores (2020).

De uma maneira geral, foi possível observar que os alunos apresentaram timidez durante as aulas expositivas, mesmo desenvolvendo as atividades, pois a participação nas aulas online era baixa e já nas aulas com a utilização do jogo Sim City 5, a participação foi maior, possibilitando um diálogo melhor com a turma e diagnóstico sobre o aprendizado do conteúdo transposto.

Já na turma do segundo ano, outros materiais também foram desenvolvidos com a elaboração de aulas com o apoio material de slides, tais como pequenos textos informativos e elaboração de mapas mentais. A diversidade de materiais elaborados tinha como foco central dinamizar as aulas e apresentar aos discentes outra perspectiva de ensino, contendo aulas dialogadas e ativas.

Do ponto de vista do contato com os alunos, foi observada uma mescla de dificuldades, preocupações e timidez. A participação ao longo das aulas era baixa, no máximo eram realizados questionamentos sobre o conteúdo ao final da aula. Ao longo das aulas o professor regente procurava trazer a participação dos discentes, entretanto em raras exceções engajaram no debate. As aulas eram tranquilas, sem interrupções ou desvios de atenção, as atividades propostas em geral eram desenvolvidas nos prazos estabelecidos, bem como dúvidas referentes às atividades eram expostas no Google Classroom, ao passo que os alunos também procuravam outros materiais complementares para compreenderem o conteúdo. 
Estágio Curricular Supervisionado em Geografia: experiência do ensino remoto durante o período de isolamento social (Covid-19)

Caio Carvalho Santos; João Vitor Ferreira Fernandes; Amanda Karolayne Rodrigues Silva; Maria Heloisa Pinheiro Dias; Rahyan de Carvalho Alves

Aulas conjuntas, com a participação das turmas do primeiro, segundo e terceiro ano do ensino médio, também foram elaboradas. O formato da aula foi organizado através do Google Meet com abordagem de temas possíveis de serem cobradas em vestibulares (principalmente o ENEM) correlacionados aos principais acontecimentos de 2020. A construção destas aulas foram focadas para haver um diálogo com os alunos, permitindo aos mesmos que a qualquer momento fossem feitos comentários, questionamentos, apontamentos de dúvidas que possuíssem e, como resultado, houve uma ampla participação dos alunos, permitindo, desta maneira, uma maior troca de conhecimentos (Vide Figura 2).

Figura 2. Aula sobre as queimadas no Pantanal.

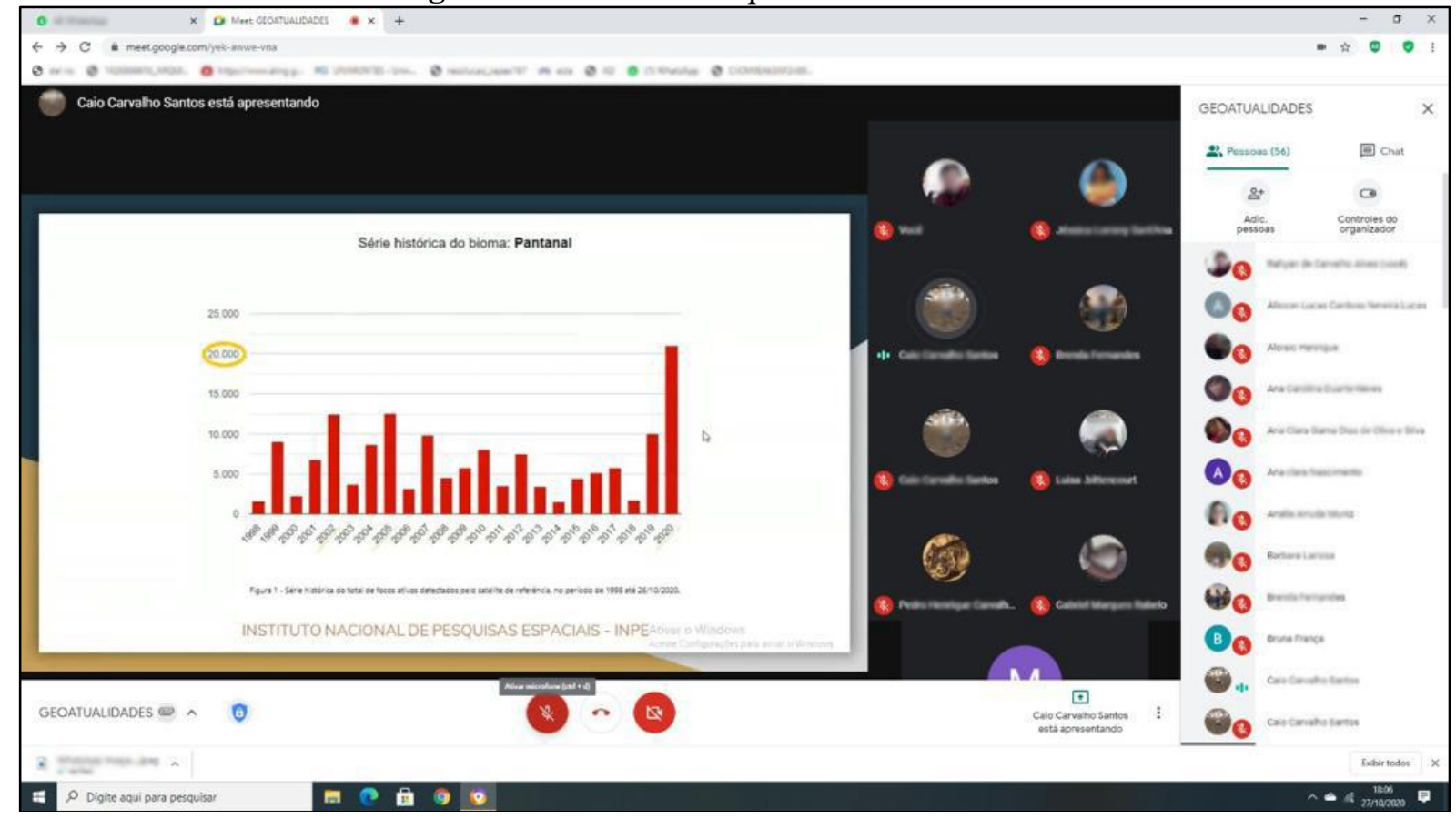

Fonte: Próprios autores (2020).

Os estágios desenvolvidos nas três escolas evidência a desigualdade no atendimento educacional direcionado a rede particular e as escolas estaduais. Enquanto a rede de ensino particular conjuntamente com seus respectivos alunos dispunha de infraestrutura necessária para atendimento das aulas remotas, as escolas públicas, apesar de terem recebido orientações, materiais digitais e suporte em aulas online não desempenharam aulas remotas e as atividades não presenciais eram precárias, justamente por causa dos alunos não possuírem aparelhos eletrônicos e acesso à internet.

Vale destacar que a posição social dos alunos também interferiu diretamente no aprendizado, uma vez que os alunos das duas escolas estaduais possuíam baixo poder aquisitivo e grande parte não se dispunham de aparelhos eletrônicos e/com acesso à internet 
Estágio Curricular Supervisionado em Geografia: experiência do ensino remoto durante o período de isolamento social (Covid-19)

Caio Carvalho Santos; João Vitor Ferreira Fernandes; Amanda Karolayne Rodrigues Silva; Maria Heloisa Pinheiro Dias; Rahyan de Carvalho Alves

para o desenvolvimento das atividades remotas, enquanto na rede particular os alunos com uma maior renda eram privilegiados com o acesso e amparo escolar para completarem o ano letivo sem maiores dificuldades.

\section{CONSIDERAÇÕES FINAIS}

As dificuldades enfrentadas pela educação, em um período de isolamento social, é infelizmente, compreensível devido às fragilidades existentes do sistema educacional convencional em nosso país. No contexto brasileiro, do ponto de vista organizacional, ficou evidente a incapacidade do estabelecimento de políticas públicas que favorecessem todas as instituições públicas de ensino e as particularidades dos seus membros discentes.

Vale mencionar que o prejuízo da educação pública brasileira no ano de 2020 não foi ocasionado pela pandemia, apenas o período de isolamento social e a possibilidade de aulas remotas evidenciaram, com mais ênfase, os problemas que as escolas e os professores têm enfrentado para o fornecimento de um ensino gratuito e de qualidade aos seus respectivos alunos (e, concomitantemente, a comunidade).

A desigualdade existente entre a escola pública e a particular foi evidenciado através da precarização do ensino remoto direcionado aos alunos das escolas estaduais, pois eles não possuíam recursos necessários (celulares, computadores, smartphones e/com acesso à internet) para desenvolverem plenamente as atividades presenciais e aulas online, enquanto a escola da rede particular, conjuntamente, com seus alunos iniciaram suas atividades com infraestrutura necessária para um ensino não-presencial.

Desta forma, enquanto a sociedade brasileira não acordar do seu profundo sono de apatia política, exigindo a devida aplicação dos impostos pagos em serviços públicos essenciais e fazer cumpri a Constituição Federal, infelizmente, continuaremos assistindo a perpetuação do sistema de ensino que representa aquilo que muitos desejam: o fortalecimento da desigualdade social e o distanciamento do conhecimento para o povo.

Observou-se em geral que as escolas tiveram grande dificuldade quanto a organização do ensino remoto, haja vista a excepcionalidade do momento, em que a diversidade de situações as quais os discentes se encontravam, representava um gargalo para a implantação de um sistema de ensino mais coeso. A inserção do estágio supervisionado neste cenário acompanhou as dificuldades já encontradas pelas escolas, onde a estruturação das aulas e intervenção do estagiário se deu de forma linear as diretrizes de ensino estabelecidas pela instituição de ensino e pelo professor da turma. A ação do estagiário possibilitou a 
Estágio Curricular Supervisionado em Geografia: experiência do ensino remoto durante o período de isolamento social (Covid-19)

Caio Carvalho Santos; João Vitor Ferreira Fernandes; Amanda Karolayne Rodrigues Silva; Maria Heloisa Pinheiro Dias; Rahyan de Carvalho Alves

dinamização/diversificação das aulas e atividades desenvolvidas, com novas ferramentas e maneiras de se abordar os conteúdos, mas em linha com a proposta estabelecida pelo professor regente.

Percebemos, nessa nossa imersão nos estágios, que os professores e equipes diretivas das escolas, mesmo com tantas limitações e desafios, lutam por uma educação pública, gratuita e de qualidade, sendo o nosso dever ajudá-los, desde agora, a mudar esse cenário, dando valor ao dinheiro público aplicado na Universidade e, assim, contribuindo para uma verdadeira transformação social.

\section{REFERÊNCIAS}

ALVES, Lynn. Educação remota: entre a ilusão e a realidade. In.: Interfaces CientíficasEducação, v. 8, n. 3, pp. 348-365, 2020.

ARRUDA, Eucídio Pimenta. Educação remota emergencial: elementos para políticas públicas na educação brasileira em tempos de Covid-19. In.: EmRede, v. 7, n. 1, pp. 257-275, 2020.

BRASIL. Lei de diretrizes de base - LDB. 1996. Disponível em: <http://www.planalto.gov.br/ccivil_03/leis/19394.htm>. Acesso: 30 de jan. 2021.

BRASIL. Portaria $n^{\mathbf{0}}$ 343, de 17 de março de 2020. 2020a. Disponível em: <https://www.in.gov.br/en/web/dou/-/portaria-n-343-de-17-de-marco-de-2020-248564376>. Acesso: 01 de jan. 2021.

BRASIL. Portaria $\mathbf{n}^{\mathbf{0}}$ 345, de 19 de março de 2020. 2020b. Disponível em: <https://www.in.gov.br/en/web/dou/-/portaria-n-345-de-19-de-marco-de-dade25125202020>. Acesso: 01 de jan. 2021.

BRASIL. Portaria $\mathbf{n}^{\mathbf{0}}$ 473, de 12 de maio de 2020. 2020c. Disponível em: <https://www.in.gov.br/en/web/dou/-/portaria-n-473-de-12-de-maio-de-20205e\%25202020>. Acesso: 01 de jan. 2021.

BRASIL. Portaria $\mathbf{n}^{\circ} \mathbf{5 4 4}$, de 16 de junho de 2020. 2020d. Disponível em: <https://www.in.gov.br/en/web/dou/-/portaria-n-544-de-16-de-junho-de-2020-2611924872>. Acesso: 01 de jan. 2021.

BRASIL. COVID-19 no Brasil e no mundo: painel coronavírus. Disponível em: <https://susanalitico.saude.gov.br/extensions/covid-19html/covid-19html.html>. Acesso: 13 de abr. 2021.

CAMACHO, Alessandra Conceição Leite Funchal et al. A tutoria na educação à distância em tempos de COVID-19: orientações relevantes. In. Research, Society and Development, v. 9, n. 5, [n. p.], 2020. 
Estágio Curricular Supervisionado em Geografia: experiência do ensino remoto durante o período de isolamento social (Covid-19)

Caio Carvalho Santos; João Vitor Ferreira Fernandes; Amanda Karolayne Rodrigues Silva; Maria Heloisa Pinheiro Dias; Rahyan de Carvalho Alves

CEEMG.Conselho Estadual de Educação de Minas Gerais. Resolução CEE no 474 de 08 de maio de 2020. 2020. Disponível em: <https://cee.educacao.mg.gov.br/index.php/legislacaocalendario-escolar-final-pandemia-covid-19>. Acesso: 30 de jan. 2021.

ESTUDE EM CASA. Regime de estudo não presencial: ensino fundamental e médio. 2020. Disponível em: <https://estudeemcasa.educacao.mg.gov.br>. Acesso: 30 de jan. 2021.

ESTÚDIO EDUCAÇÃO MG. Se liga na educação. 2020. Disponível em: <https://www.youtube.com/c/Est\%C3\%BAdioEduca\%playlist>. Acesso: 30 de jan. 2021.

FREITAS, Bruno Miranda; COSTA, Elisangela André da Silva; LIMA, Maria Socorro Lucena. O estágio curricular supervisionado e construção da profissionalidade docente. In.: Expressão Católica, v. 6, n. 1, pp. 36-42, 2017.

MARTINS, Rosa Elisabete Militz Wypyczynski; TONINI, Ivaine Maria. A importância do estágio supervisionado em Geografia na construção do saber/fazer docente. In.: Geografia Ensino \& Pesquisa, v. 20, n. 3, pp. 98-106, 2016.

MILÉO, Irlanda do Socorro de Oliveira et al. Ensino remoto emergencial e o isolamento social: a precarização da escola pública e do trabalho docente. In.: UCHOA, Antônio Marcos da Conceição; SENA, Ivânia Paula Freitas de Souza; GONÇALVES, Maria Elizabeth Souza (Orgs.). Diálogos Críticos: EAD, atividades remotas e o ensino doméstico - cadê a escola? Porto Alegre: Editora Fi, 2020. pp. 88-123.

OMS. Organização Mundial da Saúde. Coronavirus disease 2019 (COVID-19): Situation Report. - 51. 2020. Disponível em: <https://www.who.int/docs/defaultsource/coronaviruse/20200311-sitrep-51-covid-19.pdf?sfvrsn=1ba62e57_10>. Acesso: 01 de fev. 2021.

SCALABRIN, Izabel Cristina; MOLINARI, Adriana Maria Corder. A importância da prática do estágio supervisionado nas licenciaturas. In.: Revista Unar, v. 7, n. 1, [n. p.], 2013. Disponível em: <http://revistaunar.com.br/cientifica/volumes>. Acesso: 30 de jan. 2021.

SOUZA, Dominique Guimarães de; MIRANDA, Jean Carlos. Desafios da implementação do ensino remoto. In.: Boletim de Conjuntura, v. 4, n. 11, pp. 81-89, 2020.

Artigo recebido em: 20 de fevereiro de 2021.

Artigo aceito em: 13 de abril de 2021.

Artigo publicado em: 01 de maio de 2021. 